\title{
The Effect of Knowledge-sharing Relationships in the High-tech Industrial Park: The Perspective of Coordinating Mechanism
}

\author{
Yi-Ying QU \\ Business School, East China University of Political Science and Law, Shanghai, 201620, China \\ sdlzqyy@hotmail.com \\ ${ }^{*}$ Corresponding author
}

Keywords: Knowledge sharing, Coordinating mechanism, Inter-enterprises relationship, High-tech industrial park.

\begin{abstract}
In the High-Tech industrial park, the inter-enterprise knowledge sharing is the important developing force of innovation. Based on the theory of coordinating mechanism, this paper presents two types of inter-enterprises coordinating mechanism on the knowledge sharing-the formal contract orientation (FCO) and the relational contract orientation (RCO). Further, based on the two coordinating mechanisms in the process of knowledge sharing, this paper proposes three inter-enterprises knowledge-sharing relationships: (1) equal and closely coupling relationship; (2) unequal and generally coupling relationship; (3) equal and not coupling. What's more, the effects of the FCO and RCO on the knowledge-sharing relationship are discussed.
\end{abstract}

\section{Introduction}

The research institution shows that the high-tech industrial park plays the key role in promoting the innovation advantages of enterprises and the development of regional innovation [1]. In the high-tech industrial park, the innovation performance of enterprises depends on the output of inter-enterprises knowledge sharing [2]. For instance, Chang'an Automobile improved the innovation capability by integrating the advantages of electric vehicle technology in the fields of low-emission engines, energy conservation and low-carbon emission. However, in the process of knowledge sharing, the knowledge complexity and the knowledge sharing willingness produce inter-enterprises sharing conflict and even affect knowledge sharing outcomes. Hence, researchers and practitioners have particularly striven to discuss the role of coordinating mechanisms in the process of knowledge sharing. Therefore, this paper introduces two types of inter-enterprises coordinating mechanisms in the process of knowledge sharing, and argues the effect of different knowledge-sharing relationships

\section{Formal Contract Orientation and Relational Contract Orientation}

The contract in the theories of classical contract and neoclassical contract is executed as agreements in law, which refers to commitments and obligation made by players [3, 4]. Due to the transaction cost and opportunism, it is difficult to foresee and specify that what will happen and how to resolve the conflicts. Many scholars, including transaction cost economists, have observed that the governance of interorganizational transactions involves more than formal contracts. Interorganizational transactions are typically repeated exchanges embedded in social relationships. Macneil (2000) argues that formal contract is not perfect, and classical contract is replaced by relational contract in terms of contract extension and the increasing complexity [4]. Then he proposes the relational contract theory and indicates that in the complex and uncertain transaction, the contract involves relationships in addition to barter transactions [5]. Relational contract refers to informal agreements involving goals, trust, reputation, structures and culture [6]. They can facilitate the knowledge sharing and innovation performance between enterprises.

It is generally believed that there exists interaction effect of formal contracts and relational contracts. Relational contract is commonly considered as a substitute for formal contract in the transaction [7], whereas formal contract and relational contract are as complements [5]. Further, Macneil (2000) 
introduces the relational contract spectrum and demonstrates the interweaving relationship [4]. At one end of the spectrum is the formal contract, and the other end is the relational contract with the deepen interaction. Referring to the spectrum, this paper shows that in high-tech industrial park, the cooperation of knowledge sharing is riddled with the interaction of formal contract and relational contract (See figure 1). In the interaction interval, it is difficult to identify the specific percentage which is occupied by formal contracts or relational contracts, and how to justify the motivation of employing coordinating mechanisms. Therefore, formal contract orientation (from hereon: FCO) refers to the desire to take the coordinating ways denominated by formal contract agreements in short-term transaction. Meanwhile, relational contract orientation (from hereon: $\mathrm{RCO}$ ) refers to the desire to take the coordinating ways denominated by informal coordinating factors in the long-term transaction.

\begin{tabular}{lll}
$\begin{array}{l}\text { Formal } \\
\text { contract }\end{array}$ & $\begin{array}{c}\text { FCO \& RCO } \\
(\text { knowledge sharing) }\end{array}$ & $\begin{array}{l}\text { Relational } \\
\text { contract }\end{array}$ \\
\hline
\end{tabular}

Fig. 1 Coordinating mechanism spectrum

\section{Inter-enterprises Knowledge-sharing Relationships}

The firms in the high-tech industrial park need to improve the knowledge sharing outputs by choosing the relative coordinating mechanism- FCO and RCO. In the process of knowledge sharing, the aim of FCO clearly orients a certain knowledge sharing or in the short period. RCO aims to improve the reputation and the relationship position in the long-term technological cooperation.

The knowledge-sharing activities are the foundation of the formation of inter-enterprises relationship in the high-tech industrial park. In the knowledge-sharing process, the coordinating mechanisms chosen by the firms reflect the knowledge-sharing relationships between firms and then the knowledge-sharing effect (See figure 2). Three sharing relationships comprise the equal and loosely coupling relationship, the unequal and generally coupling relationship and the equal and closely coupling relationship.

\section{The Effect analysis of Knowledge-sharing Relationships}

The high-tech industrial parks provide firms with effective information which enhances the innovative activities and innovative strategy [8]. Then this study proposes that the knowledge-sharing effect can be divided into two levels: knowledge-sharing which is considered as the dynamic process of knowledge-transferring and knowledge-resonance which does not transfer the acquired knowledge into the knowledge elements base but refers to the sharing outcome occurring as a result of activating the linkages of acquired knowledge elements and knowledge base.

This study considers an economic environment consisting of two parties for better illustration of knowledge effects. In each period, the firm A may choose RCO to coordinate the knowledge-sharing relationship. Given firm A's actions, if firm B may be a newcomer or not based on the central position in the high-tech industrial parks, then it would tend to use FCO to collaborate with firm A in terms of adverse influences of lack of knowledge acquisition. In this condition, the relationship between firm A and firm B becomes an unequal and generally coupling relationship. Firm B worries about the knowledge-sharing duration and the probability of the replacement by firm A's alternative partners, in the meantime, firm A also cares for the risks derived from the trust of firm B's knowledge sharing capability. Therefore, these two partners can only contribute to the knowledge sharing not the knowledge resonance. If firm B may be the long-term partner of firm A, then it would tend to use RCO to maintain long-term cooperation to form an equal and closely coupling relationship. Thus, both sides remain consistent in the shared objectives, trust each other to share knowledge and help each other without reservation on tacit knowledge transfer and absorption of knowledge, thereby bringing knowledge resonance effect.

If both of partners are not based on the center position in the high-tech industrial park, they would tend to choose the FCO to carry out the knowledge-sharing cooperation at the beginning. Hence, it is firms in the loosely relationship that can be more flexible to break the existing contracts, but to turn to other 
partners which are more conducive to knowledge innovation. In this case, the relationship is embedded in the dynamic process of sharing knowledge where firms can reserve the knowledge base by accumulating innovation knowledge available for activation in the future. However, the sharing effect between firms is far away from knowledge resonance, and consequently the poor innovation in the park.

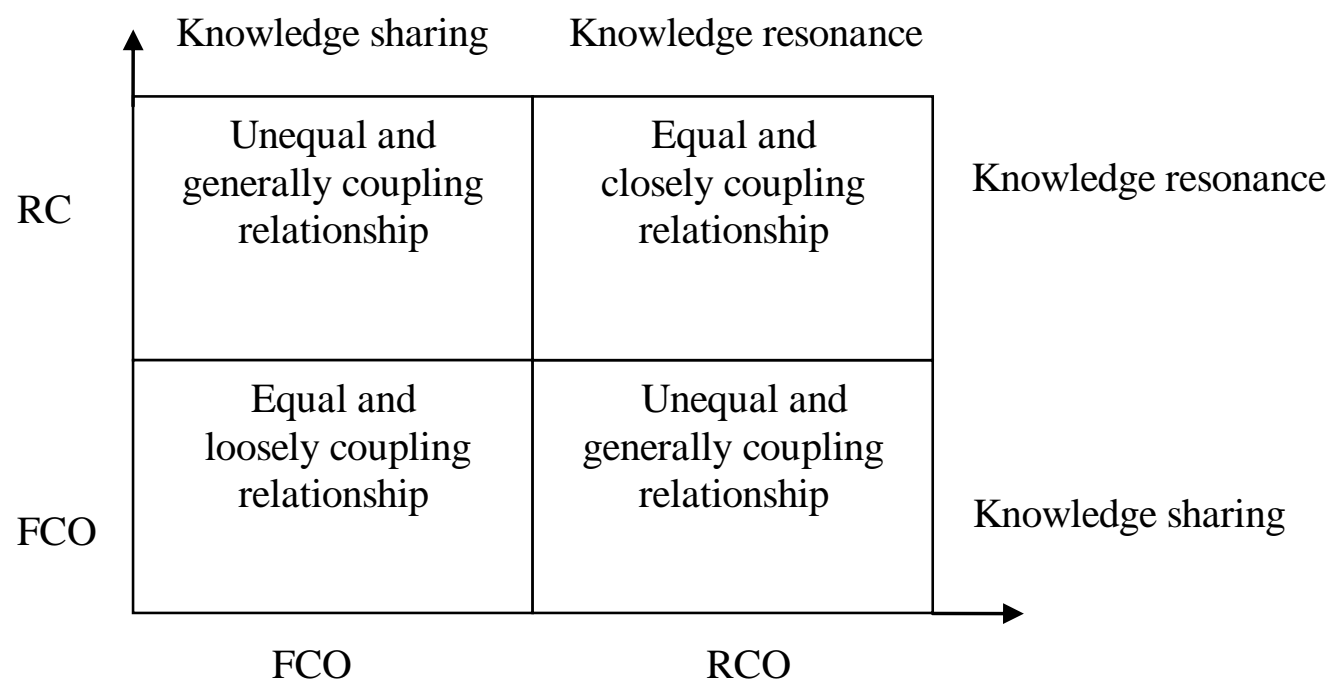

Fig. 2 Knowledge-sharing relationships and effects

\section{Conclusion}

High-tech industrial parks are the industrial clusters dominated by governments, mainly consisting of high-tech firms. They can cultivate optimal soft environment for the development of high-tech and are motivated by the collaborative innovation. The goal of the study is to provide insight in the knowledge sharing in the high-tech industrial parks by considering the value of the FCO mechanism and the RCO mechanism of sharing knowledge in the high-tech industrial parks. In the process of knowledge sharing, different strategies of employing mechanisms will form the three attributes of relationships between firms and accordingly contribute to the knowledge sharing effects. It is hoped that the effect analysis of knowledge sharing relationships will encourage researcher to conduct the game model (e.g. KMRW) necessary to further increase our understanding of inter-enterprises relationships and knowledge innovation.

\section{Acknowledgement}

This research was financially supported by Shanghai University Young Teacher Training Program, East China University of Political Science and Law under Grant 2017 Science Research Project, Shanghai Social Sciences Planning Project under Grant 2015JG009-BGL307 and the National Social Science Foundation of China under Grant 17BGL099.

\section{References}

[1] The China Industrial Park Sustainable Development Blue Book, Tongji University Press, 2017, pp.183-209.

[2] C. Yang, Y. Xia, X. Shi, Study on Intellectual Property Management and Service Modes of Park: From the Perspective of Industrial Cluster, 33 (2012) 5-10.

[3] O.E. Williamson, Comparative economics organization: the analysis of discrete structural alternatives, Administrative Science Quarterly, 36 (1991) 269-296. 
[4] I. R. Macneil, Relational contract theory: challenges and queries, Northwestern University Law Review, 94 (1998) 877- 971.

[5] L. Poppo, T. Zenger, Do formal contracts and relational governance function as substitutes or complements?, Strategic Management Journal, 23 (2002) 707-725.

[6] J.H Dyer, H. Sing, The relational view: cooperative strategy and sources of interorganizational competitive advantage, Academy of Management Review. 23 (1998) 660-679.

[7] R. Gulati, Does familiarity breed trust? The implications of repeated ties for contractual choice in alliances, Academy of Management Journal, 38(1995) 85-112.

[8] R. Aalbers, The role of contracts and trust in R\&D alliance in the Dutch biotech sector, Innovation-Management Policy \& Practice, 12 (2010) 311-329. 